\title{
Principio del interés superior del niño: dificultades en torno a su aplicación en la legislación chilena*
}

\author{
Recibido: 04 de marzo de 2018 • Aprobado: 27 de julio de 2018 \\ https://doi.org/10.22395/ojum.v18n36a1
}

Andrés Pablo Acuña Bustos"

\begin{abstract}
RESUMEN
El presente artículo ofrece una mirada del principio del interés superior del niño, niña o adolescente en la legislación chilena, y las dificultades y particularidades que este presenta al aplicarse en los tribunales dicho principio en la resolución de los conflictos sometidos a su decisión. Por medio de diversos criterios y herramientas - tanto interpretativas como concretas - los tribunales han logrado dotarlo de contenido específico para garantizar una adecuada protección, de acuerdo con el mandato de la legislación nacional. Se abordarán dogmática y analíticamente los criterios utilizados, de tal manera que sea posible concretar los límites difusos de este principio.
\end{abstract}

Palabras clave: principios interés superior; criterios judiciales; función de los principios; concepto difuso.

El presente artículo forma parte del requisito de defensa de proyecto de tesis doctoral del programa de doctorado de la Universidad de Talca, bajo la dirección de la académica y doctora en derecho Carolina Riveros Ferrada.

** Abogado y máster en Derecho de la Universidad Católica de la Santísima Concepción, Concepción, Chile, candidato a doctor en Derecho, Universidad de Talca, Talca, Chile. Académico de la Universidad de Antofagasta, Antofagasta, Chile. Correo electrónico: andres.acuna@uantof.cl 


\section{Principle of the best interests of the child: Difficulties surrounding its application in Chilean legislation}

\section{ABSTRACT}

This paper takes a look at the principle of the best interest of children and adolescents in Chilean legislation, and the difficulties and peculiarities that it presents when the courts apply it in the resolution of conflicts submitted to their judgement. Through both interpretative and concrete criteria and tools, the courts have managed to provide it with specific content in order to achieve adequate protection in accordance with the mandate by national legislation. The criteria used to that effect will be analyzed both dogmatically and analytically, in order to specify the fuzzy limits of this principle.

Keywords: best interest principles; Judicial criteria; function of the principles; diffuse concept.

\section{Princípio do nível de interesse superior da criança: dificuldades em torno à sua aplicação na legislação chilena}

\section{RESUMO}

O presente artigo oferece um olhar do princípio do interesse superior do menino, da menina e do adolescente na legislação chilena e das dificuldades e particularidades que enfrenta quando os tribunais aplicam o princípio na resolução dos conflitos submetidos à sua decisão. É por meio de diversos critérios e ferramentas, tanto interpretativas quanto concretas, que os tribunais têm conseguido dotá-lo de conteúdo específico para garantir uma proteção adequada de acordo com o imperativo que manda a legislação nacional. Os critérios utilizados para efeito de permitir concretizar os limites difusos desse princípio foram abordados dogmática e analiticamente.

Palavras-chave: princípios interesse superior; critérios judiciais; função dos princípios; conceito difuso. 


\section{INTRODUCCIÓN}

El interés superior del niño, niña o adolescente, constituye un principio fundamental en el ordenamiento jurídico chileno y de mayor relevancia para la decisión de diversas y múltiples materias judiciales. Este principio, si bien propio, mas no exclusivo del derecho familiar, alude al pleno respeto de los derechos esenciales del niño, niña o adolescente y su finalidad cubre el desarrollo de los potenciales del menor y la satisfacción de sus necesidades en los diferentes aspectos de su vida.

No pueden desconocerse los inconvenientes que existen en torno a precisar su contenido y alcance, lo que trae consigo ciertas dificultades prácticas en su aplicación en casos en los que se encuentra vinculado el resguardo y protección de los derechos de los menores de edad. De tal situación, surge la necesidad de establecer como propósito el determinar cómo los tribunales de familia chilenos concretan el sentido y alcance de este principio a la hora de tutelar los derechos de los niños, niñas y adolescentes.

En el derecho civil chileno, el interés superior del niño, como principio, tiene una composición necesariamente genérica, abierta y flexible, lo que permite su aplicación a las diversas situaciones jurídicas y sociales (Ramos, 2009) que se planteen como consecuencia de la variada realidad social que de antemano no puede ser prevista en su totalidad y a los cambios que vayan suscitándose con el devenir del tiempo (Ravetllat y Pinochet, 2015). Estas pautas y criterios deben apoyarse ineludiblemente en la consideración del niño, niña y adolescente como persona y como ciudadano y, en tanto tal, deben serle reconocidos y garantizados sus derechos fundamentales, su dignidad y el respeto al libre desarrollo de su personalidad, teniendo siempre en cuenta sus necesidades particulares.

Así, el principio del interés superior del niño, niña o adolescente se presenta en Chile como un concepto jurídico indeterminado (Gutiérrez, 2011), que necesita ser concretado en cada situación específica. Nuestro sistema normativo, al igual que el sistema normativo internacional, no se aventura a definir este principio. A falta de una definición propia, la judicatura nacional se remite a la nomenclatura propuesta por el Comité Sobre los Derechos Del Niño, de tal modo que trata el interés superior del niño como un principio jurídico de triple entidad (como derecho sustantivo, como principio interpretativo y como norma de procedimiento).

Bajo cierta perspectiva, esta indeterminación en la concreción del principio podría ser considerada una ventaja, ya que permite interpretar este principio con cierta flexibilidad al momento de enfrentar la solución de casos particulares de acuerdo con las circunstancias y contextos de estos (ya sea familiares, culturales, económicos, etc.). 
De esta ventaja, de todas formas, se desprende un elemento de incertidumbre, pues si bien el principio ofrece cierta plasticidad, también podría ser un elemento que desencadene su uso abusivo o irracional en las soluciones a un conflicto promovido ante los tribunales de familia. Por lo anterior, se analizarán diversas sentencias dictadas tanto por los tribunales de familia chilenos, sentencias de las cortes de apelaciones y pronunciamiento de la Corte Suprema al efecto, bajo el prisma de un método dogmático-analítico.

Por lo anterior es que resulta necesario, para lograr establecer y revisar los criterios utilizado por los tribunales chilenos, explorar, primeramente, cómo se regula este principio jurídico en la legislación chilena interna para luego revisar las funciones que cumple el principio, su carácter indeterminado y la búsqueda de criterios de determinación judicial y establecer cuáles son las criticas que se le formulan y que permitan proponer soluciones de concretización a este principio de carácter difuso.

\section{REGULACIÓN DEL INTERÉS SUPERIOR DEL NIÑO EN EL ORDENAMIENTO JURIDICO INTERNO}

Chile ratificó la Convención sobre los Derechos del Niño (en adelante CIDN) el 14 de agosto de 1990, posteriormente y siguiendo el mandato constitucional del artículo 5 de la Constitución Política', la legislación chilena pasó a garantizar otros derechos específicos en torno a la figura del niño², en diferentes áreas como: protección contra la violencia intrafamiliar, educación, trabajo, filiación, alimentación, adopción, salud, delitos sexuales, entre otros. Todo esto, acorde a los cuatro principales pilares de la CIDN, es decir, no discriminación, supervivencia, desarrollo y protección, participación y el interés superior del niño.

Surge la pregunta: ¿cómo los países adoptan dentro de su ordenamiento estos principios, específicamente el principio del interés superior del niño? El Comité Sobre los Derechos del Niño (2014) reconoce dos medios o sistemas utilizados por los ordenamientos jurídicos de los países suscriptores, para integrar y determinar en qué consiste el interés superior del niño, y que se analizará en el desarrollo de este trabajo.

Específicamente el inciso $2^{\circ}$ : "el ejercicio de la soberanía reconoce como limitación el respeto a los derechos esenciales que emanan de la naturaleza humana. Es deber de los órganos del Estado respetar y promover tales derechos, garantizados por esta Constitución, así como por los tratados internacionales ratificados por Chile y que se encuentren vigentes".

2 Chile tuvo que realizar una serie de modificaciones a las leyes vigentes, debido a las observaciones realizadas por el Comité sobre los derechos del Niño en abril de 1994, para así adecuar la legislación interna a los preceptos de la Convención. Esto permitió la modificación de la ley de adopción de 1999 (pone fin a la discriminación de los niños nacidos fuera del matrimonio, reconoce la filiación extramatrimonial), en el ámbito penal, se modifican normas relativas al secuestro de menores y su traslado al extranjero, modificación de normas en relación a delitos sexuales contra niños, etc. 
El primer sistema, que denominaremos de los factores significativos, proporciona una guía a seguir en la toma de decisiones donde el principio debe entrar en juego (se crean una serie de criterios o pautas), incorporando elementos de juicio y discernimiento, que controlan la arbitrariedad y eventuales riesgos en la aplicación del principio interés superior del niño. Este sistema es el seguido en su mayoría por el derecho anglosajón.

El segundo sistema corresponde al de la existencia de la cláusula general o del concepto jurídico indeterminado (Del Picó, 2016), en la que solo se impone la necesidad de actuar en el interés del menor, pero sin reconocérsele un contenido específico. Al ser considerada una cláusula general, puede abarcar un sinfín de supuestos de hecho, ampliando la capacidad de valorar judicialmente un caso concreto, sin dejar fuera lo no previsto por el legislador.

Este último sistema es el utilizado en Latinoamérica y es el lineamiento seguido por Chile. Desde un comienzo, el legislador ha demostrado poco interés en la determinación del contenido del principio, y ha entregado al juez la potestad de aplicación a través de las normas vigentes, debiendo adecuar los preceptos legales a cada proceso en particular, en virtud de las múltiples circunstancias del caso.

El principio de interés superior del niño, niña o adolescente es considerado un concepto indeterminado en Chile tal y como reconoce la Corte Suprema a través de la Sentencia causa rol 7150-2012, de 14 de enero de 2013³ (Herrera Porras con Gálvez Herrera), que en su parte pertinente expresa:

Aun cuando su concepto sea indeterminado (interés superior del niño), puede afirmarse que el mismo, alude a asegurar el ejercicio y protección de los derechos fundamentales de los menores y a posibilitar la mayor satisfacción de todos los aspectos de su vida, orientados al desarrollo de su personalidad. Dicho principio se identifica con la satisfacción plena de sus derechos, en su calidad de personas y sujetos de estos, identificándose de esta manera interés superior con los derechos del niño y del adolescente.

Con el sistema de la cláusula general o del concepto jurídico indeterminado, la ley no entrega una solución directa y general para un caso, pues esta debe ser indagada según la naturaleza del concepto y de las circunstancias. Debemos tener en cuenta las palabras de Ravetllat y Pinochet (2015):

Es evidente que la introducción de cláusulas generales en un ordenamiento jurídico acarrea sus ventajas e inconvenientes; entre los aspectos positivos podemos

No es la única sentencia al respecto, véanse también Coronado Cea con Carrillo Maraboli (Corte de Apelaciones de Concepción 2013), Heyner Mena con Capdeville Arrate (Corte de Apelaciones de Santiago 2012). 
destacar la posibilidad que se ofrece al intérprete de acomodar las soluciones a los criterios de conciencia social prevalentes en cada momento histórico. (...) Entre los aspectos negativos, en cambio, evidenciar el problema que puede llegar a plantear una interpretación personal o subjetiva de la cláusula, que puede provocar desviaciones notables sobre aquello que la conciencia social considera aceptable en un momento determinado del tiempo (p.920).

Frente a este panorama, durante los últimos años, la jurisprudencia a través de sus numerosas sentencias dictadas tanto por la Corte Suprema ${ }^{4}$ y por las cortes de apelaciones, ha optado por introducir ciertos indicadores o elementos de objetivación, que faciliten la comprensión y por consiguiente la aplicación del principio. Este proceso se ha llevado a cabo mediante la incorporación de las statutory checklist o welfare checklist ${ }^{5}$, en especial por las legislaciones española e inglesa, que incorporan una serie de criterios que se deben seguir para salvaguardar el bienestar de los menores (Ravetllat y Pinochet, 2015).

\section{EL PRINCIPIO DEL INTERÉS SUPERIOR DEL NIÑO EN LA LEGISLACIÓN CIVIL CHILENA}

Tal como se mencionó anteriormente, Chile, al ratificar la CIDN, debió incorporar dentro del ordenamiento jurídico los mandatos establecidos en ella. Así, podemos encontrar determinadas disposiciones que aluden al principio del interés superior del niño, como un criterio que debe adoptar el juez ante decisiones que afecten a los niños, estas normas son:

- Ley de Tribunales de Familia, artículo 16 inciso $2^{\circ}$ "el interés superior del niño, niña o adolescente, y su derecho a ser oído, son principios rectores que el juez de familia debe tener siempre como consideración principal en la resolución del asunto sometido a su conocimiento".

- En los procesos relativos a la familia y matrimonio, artículo 85 inciso $2^{\circ}$ de la ley de matrimonio civil "cuando existieren menores de edad comprometidos, el juez deberá considerar especialmente el interés superior del niño". Artículo 3 inciso $1^{\circ}$ de la ley de matrimonio civil, "las materias de familia reguladas por esta ley deberían ser resueltas cuidando proteger siempre el interés superior de los hijos".

- En el Código Civil, artículo 242 inciso 2: "para adoptar sus resoluciones el juez atenderá, como consideración primordial, al interés superior del hijo, y tendrá debidamente en cuenta sus opiniones, en función de su edad y madurez".

4 Sentencia causa rol 22616-2014 de 20 de mayo de 2015, sentencia causa rol 26845-2014 de 25 de mayo de 2015, sentencia causa rol 27042-2014 de 4 de junio de 2015

5 "Lista de control o comprobación de bienestar", consiste en siete criterios que las cortes deben considerar cuando toman decisiones concernientes a un niño, niña o adolescente. 
Como indicamos en el apartado anterior, el legislador chileno siguió la tendencia en Latinoamérica de la cláusula general, pero con la modificación del Código Civil por la Ley n. 20.680 de 2013, los nuevos artículos 225-2 y 229, sobre el establecimiento y ejercicio del régimen de cuidado personal, relación directa y regular (Acuña, 2014). Se presenta una aproximación al sistema anglosajón, al establecerse una guía a través de la enumeración de factores que facilitan la actuación de los tribunales de familia para determinar el interés de la persona menor de edad en lo referente al régimen de cuidado. Los mencionados artículos, si bien permiten encuadrar la labor interpretativa y la eventual decisión de un asunto, no tienen por objetivo limitar las opciones decisorias del juez y ello se manifiesta en que ambos consideran dentro de su enumeración "cualquier otro antecedente que sea relevante atendido al interés superior del hijo", concediendo una opción abierta al juez para considerar otros parámetros para la determinación del interés del niño en el caso concreto (Lepin, 2017).

Dentro de la normativa atingente, tenemos que señalar una norma de carácter procesal, pero cuya aplicación en este caso no debemos desconocer, nos referimos al denominado principio de inexcusabilidad de los tribunales de justicia, establecido en el artículo 76 inciso $2^{\circ}$ de la Constitución Política, y en el artículo 10 inciso $2^{\circ}$ del Código Orgánico de Tribunales, principio que no solo debe entenderse como una prohibición a los jueces, en orden a no poder sustraerse de conocer determinados asuntos, sino que por, sobre todo, debe entenderse como un verdadero deber, en cuanto a su obligación de resolver los conflictos jurídicos sometidos a su decisión. En este sentido, el juez llamado a resolver un asunto en donde el principio del interés superior del niño se vea involucrado, no puede evadir su aplicación tanto en el transcurso del proceso, como en la etapa de sentencia, aun cuando no existiere una norma específica para resolver el asunto, pues estando ante un principio general del derecho. Este forma parte inherente de lo que el artículo 24 del Código Civil califica como de "espíritu general de la legislación". Aún más, este principio debe considerarse en igual medida como regla moderadora e inspiradora de las actuaciones judiciales encaminadas a salvar, empleando el criterio de equidad, las lagunas legales que el sistema pudiere presentar, de acuerdo con lo prescrito en el artículo 170, Número 5 del Código de Procedimiento Civil (Orrego, 2007).

\section{FUNCIONES DEL INTERÉS SUPERIOR DEL NIÑO EN EL ORDENAMIENTO JURÍDICO CHILENO}

Habiendo señalado cómo se produce la incorporación de este principio, debemos realizar un breve análisis sobre las funciones atribuibles, pues si bien la observación n. ${ }^{\circ} 14^{6}$ del Comité Sobre los Derechos Del Niño (2014) señala tres funciones del

6 El mayor avance en este sentido a nivel internacional, lo podemos apreciar en la Observación General n. ${ }^{\circ}$ 14, recientemente adoptada en 2013. En ella, el Comité Sobre los Derechos del Niño presenta una lista de elementos a tener en cuenta a la hora de evaluar y determinar el interés superior del niño (esta lista es bastante abierta, pero permite cimentar lineamientos generales). 
principio (como derecho sustantivo, como principio interpretativo y como norma de procedimiento) podemos encontrar otras funciones reconocidas en el ordenamiento jurídico chileno.

El interés superior del niño impone una obligación en la forma en que los jueces y autoridades deban tomar decisiones, no siendo solo una guía, sino un deber al momento de decidir, para así garantizar la satisfacción plena de sus derechos. Cillero (2007) atribuye al principio el carácter de garantía respecto de asegurar y proteger los derechos fundamentales del niño?

Por otro lado, la Corte Suprema (2013) ha señalado respecto del principio que "se encuentra presente y se proyecta de todo el sistema jurídico, al erigirse como una garantía de amplitud tal que obliga no solo al legislador, sino que a todas las autoridades e instituciones y a los propios padres". De esta forma, no solo se le reconoce el carácter de garantía, sino además el carácter de pauta orientadora ${ }^{8}$, pues no solo influye en la creación, aplicación o decisión ${ }^{9}$ e interpretación ${ }^{10}$ de una norma, sino que en todas las instituciones que se vinculen a un menor.

Es innegable el sentido en cuanto a función interpretativa y de resolución de conflictos que tiene el principio del interés superior del niño en el sistema jurídico chileno. El legislador ha utilizado expresiones inequívocas en tal sentido: "para adoptar sus resoluciones el juez atenderá, como consideración primordial, al interés superior del hijo", "el juez deberá considerar especialmente el interés superior del niño", etc. En tal sentido, la Corte Suprema también se ha manifestado: "interesa de sobre manera el aporte que tiene en el ámbito de la interpretación, al constituir, una norma de resolución de conflictos jurídicos, permitiendo, decidir situaciones de colisión de derechos, según contenido y la ponderación de los que se encuentran en pugna"11.

7 "El principio del interés superior del niño como una garantía de la vigencia de los demás derechos que consagra e identifica el interés superior con la satisfacción de ellos; es decir, el principio tiene sentido en la medida en que existen derechos y titulares (sujetos de derecho) y que las autoridades se encuentran limitadas por esos derechos"

8 El Tribunal Constitucional chileno en Sentencia rol 2867-2015 de 12 de abril de 2016 así lo ha referido al momento de establecerlo, incluso como un mandato para el juez, en el entendido que este siempre debe tener en consideración principal, al momento de decidir sobre cuestiones de su competencia, tanto en un ámbito material como procedimental.

9 En este sentido, la Sentencia del Tribunal Constitucional chileno en causa rol 2867-2015 y la Sentencia de la Corte Suprema del 10 de abril de 2017, causa rol 47842-2016, han señalado que en lo relativo a su aplicación, este principio debe ser ponderado conforme a los contornos concretos de la situación juzgada.

10 Así se desprende de lo señalado en sentencia dictada por la Corte Suprema chilena con fecha 15 de julio de 2008, al establecer el principio del interés superior del niño como una regla de interpretación.

11 Corte Suprema de Chile, Sentencia rol 7150-2012 del 15 de julio de 2008. En cuanto al derecho del menor a ser oído, en causa rol 6553-2005 de la Corte de Suprema de Chile, considerando 9. También 


\section{EL CARÁCTER INDETERMINADO DE ESTE PRINCIPIO}

El interés superior del niño ha sido configurado por la mayor parte de los sistemas jurídicos europeos continentales (López, 2015) ${ }^{12}$, y sus derivados latinoamericanos como una cláusula general abstracta o un concepto jurídico indeterminado, difícil de definir y aplicar (Sánchez, 2012) ${ }^{13}$.

La doctrina germana se ha encargado de estructurar la teoría de la cláusula general, reconociendo que el concepto jurídico indeterminado está compuesto por dos estructuras: un núcleo de los conceptos (Begriffskern) y su halo (Begriffshof), (Muñoz, 2009) $)^{14}$. El primero de ellos, el núcleo fijo o "zona de certeza positiva", dentro de esta estructura el interés superior del niño según Ravetllat y Pinochet (2015) se radica en que a la persona menor de edad le interesa, ante todo, preservar su integridad física y moral, así como garantizar el desarrollo integral de su personalidad.

En la segunda estructura encontramos la zona intermedia o de incertidumbre, aquella que da pie a diversas posibilidades, requiere de un juicio de valor, tanto o más amplio a medida que el concepto deja de ser técnico o especializado y se inserta en lo cultural o valorativo. En la zona de certeza negativa, que hace referencia al punto o margen a partir del cual desaparece el valor implícito en el concepto, ya no se encuentra presente el interés superior del niño. Como ejemplo tenemos el caso de uno niño no puede ser confiado a un sujeto depravado o violento.

Lo anterior, hace evidente que la dificultad a la hora de precisar en qué consiste el interés superior del niño no la encontramos en la zona de certeza positiva ni en la

en causa rol 10358-2013 de la Corte Suprema. En dichas sentencias podemos ver el criterio adoptado por la Corte Suprema al momento de ponderar los conflictos de derecho y la prevalencia del interes superior del niño.

12 El principio de interés superior de los niños y niñas como el eje fundamental en cada uno de los procesos donde interviene un niño, una niña o un sujeto adolescente, toda vez que este principio forma parte del sistema de protección de los derechos de la niñez, el cual goza de reconocimiento universal desde la Declaración de Ginebra sobre los Derechos de los Niños, aprobada por la Sociedad de Naciones el 26 de diciembre de 1924, hasta la Convención sobre los Derechos de los Niños y Niñas adoptada por la Asamblea General de las Naciones Unidas el 20 de noviembre de 1989

13 La familia del subsistema de Derecho Europeo Continental: se hace referencia a la familia jurídica que comprende la mayor parte de los sistemas parlamentarios centroeuropeos y mediterráneos donde prima una visión deductiva, además de normativa, confiriéndose mayor importancia a la ley como fuente de derecho. También, de ahí, la preferencia por el derecho escrito, de carácter técnico jurídico, y tutelado por la administración bajo la excusa de bienestar social.

14 Siguiendo la doctrina alemana y su teoría del margen de la apreciación (Beurteilungsspielraum), se puede distinguir que un concepto jurídico indeterminado está compuesto por "un núcleo de los conceptos" (Begriffskern) y su halo (Begriffshof) y que el primero delimita un ámbito de absoluta certeza sobre la significación del concepto, mientras que el segundo marca la zona de incertidumbre que existe en cualquier concepto jurídico, y que es más amplia en el caso de los conceptos jurídicos indeterminados". 
zona de certeza negativa, sino justamente en la zona intermedia o de incertidumbre en que se radica la complejidad de elección y decisión ${ }^{15}$. Por lo tanto las dificultades propias de las normas que incorporan conceptos jurídicos indeterminados, radica en las personas u organismos que deben llevarlo a la práctica, ya que sobre ellos recae una doble labor: primero precisar el significado y contenido del concepto y, segundo, comprobar en qué situaciones y circunstancias concretas de las posibles, se da el valor que ha pretendido captar la norma, dando una relevancia a los datos y circunstancias del caso concreto, porque estos darán solución a la zona de incertidumbre del concepto (Ravetllat y Pinochet, 2015). Por lo tanto, pretender definir lo que debe entenderse como interés superior del niño es una tarea compleja.

La búsqueda de un significado a esta cláusula general sería contraria a la propia finalidad que la inspira: el otorgarle contenido va en franca rivalidad con su esencia, pero sentadas las bases que deben regir en cada momento nuestra conducta respecto de la interacción con el principio del interés superior del niño, nos habilita para construir ciertas directrices que darán valor y seguridad a una aproximación de su significado.

El principio del interés superior del niño, niña o adolescente, pone acertadamente el acento en su realidad como sujeto titular de derecho digno de atención y protección. Este principio ha de aplicarse en todas aquellas situaciones o conflictos donde se hallen involucrados menores de edad, pues es un principio cardinal y preponderante en la toma de decisiones de los órganos jurisdiccionales respectivos. Se debe recalcar que este concepto no se encuentra vacío, tiene contornos delimitados, cuya finalidad esencial es asegurar la efectividad de los derechos de las personas que por su condición de inmadurez no pueden actuar por sí mismas, para reclamar su protección.

Es fundamental comenzar con una reconstrucción ideológica del principio del interés superior del niño partiendo del menor como persona, como sujeto de derecho, como la mayor riqueza de nuestra sociedad.

El principio es concebido por los órganos jurisdiccionales como un concepto abstracto que otorga cierto grado de autonomía jurídica, según las circunstancias presentes en cada caso concreto. Por lo mismo, ciertos autores aplauden esa ambigüedad ya que la consideran como el elemento esencial que faculta al juez para acercarse a la verdadera situación en la que se halla un niño y decidir, con conocimiento de causa, lo más favorable para él (Bo y Caballero Rivera, 2006).

15 Pero debemos mencionar que existe una posición crítica a la teoría alemana, que la componen la doctrina española, cuyos representantes introducen una tercera estructura a los actos jurídicos indeterminados, siendo de más antigua data que esta. 
El interés superior del niño como concepto no debe ser interpretado en una forma estática, sino que, por el contrario, deberá entenderse en una forma dinámica, flexible, de manera que podamos ir perfilando caso a caso una concreción acerca de su contenido. Respetando la autonomía progresiva de niño (Barcia, 2016), su dignidad y su calidad de sujeto de derecho, con la finalidad de garantizar al niño el ejercicio y satisfacción de los derechos y garantías que surgen de su condición de persona humana, los que deben ser respetados en el ejercicio de la autoridad de los progenitores, en las resoluciones que dicten los jueces y en las medidas que tomen los organismos públicos y privados al respecto (Gómez, 2007).

Por ende, el principio del interés superior del niño se identifica con la dignidad (López, 2015), como atributo o condición intrínseca del ser humano, que dota al hombre de ciertos derechos inalienables que deben ser respetados y protegidos. Tratándose de un niño, no se puede prescindir para identificar su bienestar de referencias relativas a su edad y capacidad de raciocinio, felicidad, equilibrio emocional y afectivo, necesidades físicas y educativas, todas ellas vinculadas al cambio de circunstancia y el entorno del individuo, que contribuye a la formación y desarrollo de su personalidad como realidad humana concreta.

El principio del interés superior del niño, como ya se ha esbozado a lo largo de este artículo, escapa del positivismo, al ser su característica principal el de ser un concepto jurídico indeterminado. Dicha premisa no debe llevarnos a caer en el error de creer que esta imprecisión en su contenido se traduce en una indeterminación de su aplicación, por el contrario, su uso está estrictamente delimitado a dar una única solución justa, la cual es resultado de la relación sujeto-objeto, de carácter cognoscitivo, no estando presente el paradigma de la intersubjetividad. Por ende, el ejercicio de una potestad discrecional que permita la intromisión volitiva del sentenciador para hacer uso de una pluralidad de soluciones equitativas y justas no está permitida como medio interpretativo para dar solución a los casos contenciosos en los cuales está presente el interés superior del niño.

En el ámbito de la función jurisdiccional, la discrecionalidad jurídica es la libertad que tienen los sentenciadores para tomar decisiones y elegir entre diferentes opciones igualmente justas, por ende, la discreción se concibe como el poder o la facultad de elegir entre dos o más cursos de acción acordes con el derecho, pero en la carencia de estándares jurídicos que guíen la toma de decisión. En cambio, el concepto jurídico indeterminado exige por parte de la persona u órgano que ha de llevarlo a la práctica una doble labor: precisar el significado y contenido del concepto y, después, comprobar en qué situación y circunstancias concretas de las posibles se da el valor que ha pretendido captar la norma, dando una relevancia inusitada a los 
datos y circunstancias del caso concreto, porque estos serán los que permitan dar una solución dentro del ámbito de apreciación y variabilidad del concepto jurídico indeterminado.

Resulta importante destacar que la autoridad judicial se encuentra legitimada para fiscalizar su aplicación y valorar si la solución que con ella se ha alcanzado es la única respuesta justa que la ley permite.

El interés superior del niño se configura en el mismo instante de su aplicación, y otorga una única solución justa que es determinada por ley. Por lo tanto, a pesar de que sean los órganos públicos y privados los encargados de precisar el alcance del interés superior del niño, les está prohibido decidir de forma discrecional y arbitraria su contenido, ya que este debe ser determinado según las circunstancias de cada supuesto de hecho o caso concreto.

\section{UNA FORMA DE CONCRETAR SU INDETERMINACIÓN: OBJETIVACIÓN DEL PRINCIPIO DEL INTERÉS SUPERIOR DEL NIÑO}

Es transcendental mencionar que, conforme transcurre el tiempo, el legislador chileno se ha percatado de la importancia y relevancia de un nuevo cambio de paradigma, incorporando nuevas técnicas que guíen a nuestros jueces en la evaluación y determinación del interés superior del niño. Es importante mencionar que estos cambios son el reflejo de una tendencia que se viene desarrollando con la evolución que ha experimentado la teoría analítica del derecho, el eje central de esta nueva orientación es la objetivación de los sistemas jurídicos (Orrego, 2009). Esto se materializa a través de la objetividad prudencial de los jueces al dar respuestas a casos concretos de conocimiento jurídico práctico, a través de parámetros objetivos de decisión, los cuales parcialmente pueden contener reglas que sean a su vez generales. La objetividad no es una simple condición deseable del conocimiento científico, sino un ideal ético-político que han de realizar personas de carne y hueso (Orrego, 2009), cuyo fin será la determinación del derecho justo.

Así, el interés superior del niño busca ser objetivado para evitar los problemas de obediencia que se pueden suscitar respecto de los jueces, cuando sus razonamientos se desvían de la realidad por sus pasiones, intereses y voluntad. En este caso es necesario recurrir a fuentes ajenas al sistema jurídico, incluso los jueces, para poder decidir adecuadamente conforme a derecho, deberán ejercer una discrecionalidad no irracional sino guiada por reglas fundadas en fuentes sociales (Güitron, 2016), o principios jurídicos. 
Como se puede dilucidar, es aquí donde aparecen los criterios de valoración y ponderación, como herramientas útiles a disposición de los jueces para resolver los asuntos relacionados con menores que sean sometidos a su conocimiento. Es el ordenamiento jurídico anglosajón el primero en adoptar parámetros para determinar el bienestar del niño (welfare child) estableciendo una lista de consideraciones que los jueces deben tener presente al momento de elaborar dicho bienestar. Nuestro legislador se ha encargado de recepcionar el modelo inglés a través de un sistema de carácter mixto, y ha optado por incorporar, junto con enunciados legales de tipo cláusula general, un elenco de criterios indicativos que pretenden especificar y facilitar la búsqueda del interés superior del niño ${ }^{16}$. Son de suma relevancia y dignas de destacar las reformas introducidas por la Ley 20.680, que establece modificaciones a la normativa que regula el cuidado personal y el régimen de relación directa y regular, con el progenitor no custodio, incorporando en los artículos 225-2 y 229 del Código Civil chileno, un elenco de indicadores que permitirán a los tribunales determinar el interés superior del niño conforme al caso concreto.

El sistema de objetivación del interés superior del niño no está exento de reproches o reparos: puede provocar una rigidez excesiva, ya que una construcción jurídica que tenga como base la previsión de todas y cada una de las situaciones en que puede encontrarse el menor es peligrosa, en tanto que puede dejar fuera situaciones impensables en el momento en que se redacta el precepto. Riesgo que, no obstante, se ve superado con la inclusión de una cláusula de cierre abierta que dé cabida a cualquiera nueva circunstancia que pueda ir surgiendo (Ravetllat y Pinochet, 2015). Es así como se logran superar las críticas y se intenta dar viabilidad a la implementación de este nuevo sistema.

\section{CRÍTICAS AL SISTEMA CHILENO PARA LA DETERMINACIÓN DEL INTERÉS SUPERIOR DEL NIÑO}

La creación y aplicación de criterios constituye un modo de superar las dificultades a las cuales se ven enfrentados los jueces, en la determinación de un concepto jurídico indeterminado como es el interés superior del niño y eventualmente superar la discrecionalidad en sus decisiones. Puesto que, como se dijo anteriormente, la discrecionalidad es la opción ante la ausencia de regulación, como margen de libertad que tiene un juez para resolver y tomar una decisión. La falta de definición y contenido específico del interés superior del niño es uno de los grandes problemas que enfren-

16 En este sentido, el protocolo iberoamericano de actuación judicial para mejorar el acceso a la justicia de las personas y grupos en condiciones de vulnerabilidad con especial énfasis en el enfoque de género, ha entregado a los jueces diversos criterios que deben utilizar tales como que los juzgadores deben ir más allá de la afectación directa y previsible en una niña o niño que pudiera estar involucrado, incluyendo la protección del niño, aun cuando sea ajeno a la acción misma, pero bajo la consideración de que pudiera resultar afectado entre otros que se enumeran y se puede consultar en Cumbre Judicial Latinoamericana (2013, pp. 30-31). 
tan los especialistas jurídicos (jueces, abogados, defensores públicos, etc.), y pone en riesgo la efectiva protección de los derechos y garantías de los menores de edad.

Como se ha planteado en varias ocasiones, Chile se adscribe al lineamiento de la cláusula general o abstracta en este tema. Pero esta situación no está exenta de críticas, ya que otorga un alto grado de libertad a los jueces al momento de decidir asuntos en los que el interés superior de una persona menor de edad este en juego. El gran peligro es que los jueces fallen de manera subjetiva, caprichosa y sin lineamientos definidos, en determinados asuntos que no se pueden alejar las pasiones, prejuicios y convicciones personales de lo decisorio. Por lo cual se hace necesario un cambio o modificación de paradigma en torno a este tema, en lo que respecta a limitar la libertad interpretativa de los jueces y realizar lineamientos en la forma como los jueces deben evaluar y determinar el interés superior del niño.

Se agrega a lo anterior, la falta de iniciativa para construir el interés superior del niño por parte de la Corte Suprema, en los momentos de fallar asuntos en los cuales estén involucrados o puedan verse afectados menores de edad. Sus intentos, en la mayoría de los casos, han sido deficientes. Por ejemplo, la modificación que introdujo la Ley n. ${ }^{\circ} 20.680^{17}$, en el nuevo artículo $225-2$, en la cual se incorporan ciertos criterios y circunstancias que deben ser ponderadas al momento de decidir sobre el cuidado personal del menor. A pesar de esta modificación, la Corte Suprema no ha sido capaz de resolver los conflictos en esta materia, aplicando y desarrollando cada uno de estos parámetros, como fundamento de su decisión. Continúa fallando de manera escueta, refiriéndose tangencialmente al interés superior del niño, pero no del niño en particular, sino de forma general, y en ciertas ocasiones sobre las convicciones personales de los propios ministros en torno al caso.

Consecuencia de lo anterior, ante el escaso perfeccionamiento del tema por parte de la Corte Suprema, podemos apreciar carencias en la preparación técnica de los jueces de instancias inferiores, quienes desconocen, en ocasiones, el carácter de primacía del interés superior del niño, cayendo en el grave error, de fundamentar sus fallos solo a través de la aplicación positiva de las normas, privilegiando los interés de los progenitores o de la sociedad en general, en desmedro del beneficio o provecho de la persona menor de edad, citando el interés superior de manera enunciativa, o bien empleándolo como argumento genérico de su decisiones.

Otro factor visible en este tema es el centralismo jurídico y los problemas de acceso efectivo a la justicia ${ }^{18}$ (como medio de resolución de conflictos que afecten a

17 Introduce modificaciones al Código Civil y a otros cuerpos legales, con el objeto de proteger la integridad del menor en caso de que sus padres vivan separados.

18 Para tal efecto la Corte Suprema chilena el año 2014 trabajó en un protocolo Iberoamericano de actuación judicial para mejorar el acceso a la justicia de las personas y grupos en condiciones de 
un menor). Esto debido a la extensión geográfica chilena, las comunas o localidades más alejadas de la capital del país, carecen de los recursos humanos, económicos y técnicos necesarios para garantizar una adecuada protección a los derechos y garantías de los menores o de instituciones idóneas que brinden tal estándar. Ejemplo es el caso de causas en materia de familia que son tramitadas y seguidas ante un juzgado de competencia común en comunas alejadas de la ciudad asiento de corte y de la zona central del país, ambas partes representadas por la Corporación de Asistencia Judicial y las consecuentes limitaciones para poder ocurrir para ante la Corte Suprema (ubicada geográficamente en la capital) para el caso de poder recurrir por las respectivas vías procedimentales idóneas.

Es importante mencionar que la realidad legislativa de nuestro país es totalmente contraria a la de nuestros vecinos, como Perú (Rosas, 2017), que incluso regula constitucionalmente este principio, y Argentina, que a través de un gran esfuerzo se han esmerado por cumplir de forma efectiva los estándares establecidos por la CIDN, realidad que no traspasa nuestra frontera. El 14 de agosto de 1990 Chile ratificó la CIDN, pero a la fecha nuestro país es el único en América del Sur que aún no cuenta con un código o ley de protección de las niñas, niños y adolescentes. Como dato histórico y anecdótico, el único antecedente que se tiene respecto de una normativa de defensa de la infancia es el Decreto n. 2465 de 1979 o Ley Orgánica de Creación del Servicio Nacional de Menores.

Como resultado de una serie de sucesos desafortunados, nuestro ordenamiento jurídico solo se encarga de nombrar el principio del interés superior del niño. Pero en ninguna norma, artículo o inciso se menciona de forma expresa en qué consiste aquel. Por ello, digno de destacar e imitar, es el desarrollo que han realizado Argentina ${ }^{19} \mathrm{y}$ Venezuela ${ }^{20}$ en la objetivación del interés superior del niño, quienes se han acercado a un modelo mixto incorporando criterios indicativos, para determinar los alcances de dicho interés.

La indeterminación del interés superior y el deficiente desarrollo de esta materia en Chile tiene como resultado en no pocas ocasiones, resoluciones deficientes, ejemplo de ello lo podemos apreciar en la intervención a nivel regional de la Corte Interamericana

vulnerabilidad con especial énfasis en el enfoque de género, en donde se detallan las problemáticas de los diversos grupos vulnerables, en especial los menores, para poder acceder a un sistema que asegure sus derechos con eficacia (Cumbre Judicial Latinoamericana, 2013).

19 Ley de Protección Integral de los Derechos de las Niñas, Niños y Adolescentes y el Decreto 415/2006 de reglamentación de la Ley n. 26061 del 17 de abril de 2006 (Argentina).

20 Ley Orgánica de Protección del Niño y del Adolescente, Ley n. 5266 del 2 de octubre de 1998 (Venezuela), artículo $8^{\circ}$. Interés superior de niños, niñas y adolescentes. 
de Derechos Humanos (en adelante Corte IDH) ${ }^{21}$. En el caso particular de Chile, la jueza Karen Atala ${ }^{22}$ demandó al Estado chileno, debido a que la Corte Suprema, conociendo de un recurso de queja, otorgó la custodia definitiva y el cuidado personal de sus tres hijas al padre de estas, debido a su orientación sexual y convivencia con su pareja del mismo sexo. La Corte Suprema argumentó posibles riesgos o daños que podría conllevar a las menores la orientación sexual de la madre, fundamentando su resolución en la prioridad del "Interés Superior del Niño sobre otras consideraciones y derechos relativos a sus progenitores", otorgando prevalencia a la solicitud del padre de obtener la custodia del cuidado de sus hijas, desconociendo los derechos de la madre y omitiendo el respeto al derecho de las menores a ser escuchadas y tener su opinión en cuenta, establecido en el artículo 12 de la CIDN.

En este caso, la Corte IDH entiende que la sola referencia al "Interés Superior del Niño", que realizó la Corte Suprema, sin probar en concreto los riesgos o daños que podrían conllevar la orientación sexual de la madre para las niñas, no podía servir de medida idónea para la restricción de un derecho protegido, como el de poder ejercer todos los derechos humanos sin discriminación alguna por la orientación sexual de la persona. La Corte Suprema consideró que las niñas se encontraban en una situación de riesgo, ubicándolas en un estado de vulnerabilidad en su medio social, es decir, que al no compartir el entorno familiar de sus demás compañeros (progenitores heterosexuales), aumentaban significativamente el riesgo de ser aisladas y discriminadas, lo que afectaba su desarrollo personal. Pero en ningún momento las niñas fueron escuchadas y consideradas sus opiniones ${ }^{23}$, por lo que se estima que la Corte Suprema incurrió en simples especulaciones. Considerando que, en los casos de cuidado y custodia de menores de edad, no pueden ser admisibles las especulaciones, presunciones, estereotipos o consideraciones generalizadas sobre características personales de los progenitores o preferencias culturales respecto a ciertos conceptos tradicionales de la familia ${ }^{24} \mathrm{y}$ en especial teniendo en consideración lo dispuesto por la Observación

21 La Corte IDH desarrolla dos tareas dentro del sistema interamericano, por un lado la competencia consultiva, y por otro la competencia contenciosa, que nos interesa en este punto. En virtud de ésta última facultad, la Corte conoce de las violaciones de derechos humanos cometidos por los Estados partes, pronunciándose a través de sus resoluciones a fin de imponer reparación.

22 Caso Atala Riffo y niñas vs. Chile (Corte Interamericana de Derechos Humanos, 2012).

23 Este es otro de los graves problemas existentes en el ámbito judicial chileno, la poca cabida a la posibilidad de oír a los menores. El artículo 12 de la CIDN garantiza "al niño que esté en condiciones de formarse un juicio propio el derecho a expresar su opinión libremente en todos los asuntos que afecten al niño, teniéndose debidamente en cuenta las opiniones del niño, en función de la edad y madurez del niño". Para profundizar sobre el particular, consultar El niño como sujeto de derechos y la nueva justicia de familia, interés superior del niño, autonomía progresiva y derecho a ser oído", de Jaime Couso (2006), artículo sobre las clases ofrecidas en el marco del Seminario Internacional Sobre Derecho de Familia e infancia, para el VIII curso de Protección Jurisdiccional de Derechos del Niño dictado en Paraguay en octubre 2005.

24 En el mismo sentido recientes sentencias dictadas por la Corte Suprema chilena en causa rol 4827-2017 y sentencia dictada por la ilustrísima Corte de Apelaciones de Concepción en causa rol 252-2017. 
general n. ${ }^{\circ} 14$ (2013) sobre el derecho del niño a que su interés superior sea una consideración primordial (artículo 3, párrafo 1).

\section{CONCLUSIONES}

La concreción de este principio debe hacerse a la luz de interpretaciones que abarquen hechos concretos y reales, evitando así la determinación a partir de presunciones infundadas y estereotipadas sobre la capacidad e idoneidad parental de poder garantizar el fin legítimo de proteger el interés superior del niño. La tarea de determinación del interés superior se vería facilitada si se establecen normativamente parámetros, factores o criterios a revisar y tener en cuenta por los tribunales al momento de decidir. Estos criterios ayudarían en gran medida a superar las consideraciones de elementos ajenos al bienestar real y efectivo que representa el interés superior de un menor.

Determinar qué es lo mejor para un niño, es un proceso delicado y complejo para los jueces. Por lo tanto, las circunstancias y datos pueden transformarse en una fuente de poder decisional importante. El interés superior del niño, al ser un principio de estructura abierta y de múltiples significados, otorga al juez la libertad para decidir conforme los resultados que arroje la evaluación personal que realice de la situación (Thury, 2003). En cambio, si ese principio se concreta en una serie de definiciones y aplicaciones que limiten a los decisores futuras, el principio del interés superior del niño dejará de ser una mera norma de habilitación discrecional para los jueces, y se configurará con parámetros que limitarían el margen actual de decisión.

Por lo tanto, en la medida en que el principio concreta su significado de modo general, a través de la fijación de reglas decisorias o procedimentales, el poder del intérprete decrece y su actuación se hace más previsible. La juridicidad u objetivación del principio del interés superior del niño, tiene dos funciones principales: la primera es accionar a los legisladores para la emisión de normas generales, que ayuden a los jueces en la creación de estándares jurisprudenciales. Y segundo, asegurar la efectiva protección de los derechos de los niños, a través de la limitación impuesta a los jueces al momento de decidir.

Se podría hablar de una tarea de autolimitación: los jueces descartarían en lo posible una interpretación discrecional, y así encuadrarían sus márgenes de decisión en aras de una construcción jurídica, que tendrá como finalidad condicionar sus actuaciones futuras, asentando jurisprudencialmente la aplicación de estos parámetros, criterios o factores. La judicialización de este principio trae aparejado grandes avances, no solo en el hecho de poder establecer criterios jurisprudenciales que sean vinculantes dentro de los tribunales de justicia, sino que también, a través de su limitación, se logra proteger de forma más efectiva y eficiente los derechos de los niños. 
Por ello, la gran tarea de Chile es procurar avanzar en esta materia, en la búsqueda de determinar el contenido específico del interés de la persona menor de edad, no en un interés general, puesto que los contextos y circunstancias dependen de cada niño, sino en la búsqueda del interés particular o específico para cada caso en concreto. Labor que solo se vería facilitada con la creación de criterios o factores para tener en cuenta, por parte de los jueces, tal como si se tratase de una lista enumerada, chequear obligatoriamente cada uno de estos criterios y una vez realizado este ejercicio, y sobre la base de la información recabada, decidir cuál sería la resolución que de mejor manera asegure el resguardo del principio de interés superior del niño, niña o adolescente.

\section{REFERENCIAS}

Acuña, M. (2014). Derecho de relación directa y regular. Santiago de Chile: Thomson Reuters.

Barcia, R. (2016). Estudios de derecho de familia. Actas primeras jornadas nacionales Facultad de Derecho Universidad de Chile. Santiago de Chile: Thomson Reuters.

Bo, J. y Caballero Rivera, M. (2006). El nuevo derecho del menor a ser oído: ¿Sujeto activo en la determinación de su interés? Revista Jurídica La Ley, 4166, 1485-1498.

Chile. Corte de Apelaciones de Concepción. (2017). Sentencia causa rol 252-2017, Inostroza Rivera.

Chile. Corte Suprema de Justicia. (2005). Sentencia causa rol 6553-2005, Méndez con Ernst.

Chile. Corte Suprema de Justicia. (2008). Sentencia causa rol 3202-2008, Arriola y Donoso con Tapia.

Chile. Corte Suprema de Justicia. (2013). Sentencia causa rol 7150-2012, Herrera Porras con Gálvez Herrera.

Chile. Corte Suprema de Justicia. (2013). Sentencia causa rol 10358-2013, Solís con Soto.

Chile. Corte Suprema de Justicia. (2015). Sentencia causa rol 22616-2014, Montenegro con Schmitt.

Chile. Corte Suprema de Justicia. (2015). Sentencia causa rol 26845-2014, Zapata con Chamorro.

Chile. Corte Suprema de Justicia. (2015). Sentencia causa rol 27042-2014, Rejano con Torres.

Chile. Corte Suprema de Justicia. (2017). Sentencia causa rol 47842-2016, Ignaipil con Inostroza.

Chile. Corte Suprema de Justicia. (2017). Sentencia causa rol 4827-2017, Cid con Barria.

Chile. Tribunal Constitucional. (12, 04, 2016). Sentencia rol 2867-2015. Recuperado de http://www. tribunalconstitucional.cl/expedientes?rol=2867

Cillero, M. (2007). El interés superior del niño en el marco de la Convención Internacional sobre los Derechos del Niño. Revista Justicia y Derechos del Niño (UNICEF), 9, 125-142.

Comité Sobre los Derechos del Niño. (2014). Observaciones generales del Comité de los Derechos del Niño. Recuperado de https://www.unicef.org/ecuador/UNICEF-ObservacionesGeneralesDel ComiteDeLosDerechosDelNino-WEB.pdf 
Corte Interamericana de Derechos Humanos. (2012). Caso Atala Riffo y niñas vs. Chile. Recuperado de http://corteidh.or.cr/docs/casos/articulos/seriec_239_esp.pdf

Couso, J. (2006). El niño como sujeto de derechos y la nueva justicia de familia, interés superior del niño, autonomía progresiva y derecho a ser oído. Revista de Derechos del Niño, (3-4), 145-167.

Cumbre Judicial Latinoamericana. (2013). Protocolo iberoamericano de actuación judicial para mejorar el acceso a la justicia de las personas y grupos en condiciones de vulnerabilidad con especial énfasis en el enfoque de género. Recuperado de http://anterior.cumbrejudicial.org/c/ document_library/get_file?p___id=587623\&folderId=675878Ename=DLFE-5897.pdf

Del Picó, J. (2016). Derecho de familia: colección de tratados y manuales. Santiago de Chile: Thomson Reuters.

Gómez, M. (2007). El sistema filiativo chileno. Santiago de Chile: Editorial Jurídica de Chile.

Güitron, J. (2016). Estudios de derecho de familia. Actas primeras jornadas nacionales Facultad de Derecho Universidad de Chile. Santiago de Chile: Thomson Reuters.

Gutiérrez, P. (2011). La constitucionalización del derecho civil. Principios jurídicos, análisis y crítica. Santiago de Chile: Thomson Reuters.

Lepin, C. (2017). Derecho familiar chileno. Santiago de Chile: Thomson Reuters.

López, R. (2015). Interés superior de los niños y niñas: definición y contenido. Revista Latinoamericana de Ciencias Sociales, Niñez y Juventud, 13, 51-70.

Muñoz, S. (2009). Tratado de derecho administrativo y derecho público en general. Madrid: Editorial Boletín Oficial del Estado.

Organización de las Naciones Unidas. (1989). Convención sobre los derechos del niño. Recuperado de https://www.ohchr.org/SP/ProfessionalInterest/Pages/CRC.aspx

Orrego, J. (2007). Temas de derecho de familia. Santiago de Chile: Sociedad Editora Metropolitana.

Orrego, C. (2009). La objetividad del derecho como función de la subjetividad/objetividad del juez. Revista de Derecho Valparaíso, (33), 607-609.

Ramos, R. (2009). Derecho de familia. Santiago de Chile: Editorial Jurídica de Chile.

Ravetllat, I. y Pinochet, R. (2015). Interés superior del niño en el marco de la Convención internacional sobre los derechos del niño y su configuración en el derecho civil chileno. Revista Chilena de Derecho,42(3), 918-924.

Rosas, C. (2017). Reflexiones sobre la Convención Internacional de los Derechos del Niño. Revista Persona y Familia, 1(5), 65-79.

Sánchez, A. (2012). Sistema de derecho comparado y global: de las familias jurídicas mundiales al nuevo derecho común. Valencia: Editorial Tirant lo Blanch.

Thury, V. (2003). En el nombre del niño: el interés superior del menor en la construcción del rol de la Corte Suprema. Revista Discusiones, 13(2),169-210. 